Portland State University

PDXScholar

\title{
Mitigating High-Skill Brain Drain in Low-Growth \\ Economies: An Examination of Existing Brain-Drain Threats in New Mexico and Strategy and Policy Alternative to Address Them
}

\author{
Aaron T. Cowan \\ University of New Mexico \\ Kelly R. Cowan \\ Portland State University, kcowangm@gmail.com \\ Steven T. Walsh \\ University of New Mexico
}

Follow this and additional works at: https://pdxscholar.library.pdx.edu/etm_fac

Part of the Economics Commons, and the Human Resources Management Commons Let us know how access to this document benefits you.

\section{Citation Details}

A. T. Cowan, K. R. Cowan and S. T. Walsh, "Mitigating High-Skill Brain Drain in Low-Growth Economies: An Examination of Existing Brain-Drain Threats in New Mexico and Strategy and Policy Alternative to Address Them," 2019 Portland International Conference on Management of Engineering and Technology (PICMET), Portland, OR, USA, 2019, pp. 1-8.

This Article is brought to you for free and open access. It has been accepted for inclusion in Engineering and Technology Management Faculty Publications and Presentations by an authorized administrator of PDXScholar. Please contact us if we can make this document more accessible: pdxscholar@pdx.edu. 


\title{
Mitigating High-Skill Brain Drain in Low-Growth Economies
}

\author{
An Examination of Existing Brain-Drain Threats in New Mexico and Strategy and Policy \\ Alternative to Address Them
}

\author{
Aaron T. Cowan ${ }^{1}$, Kelly R. Cowan ${ }^{2}$, Steven T. Walsh ${ }^{3}$ \\ ${ }^{1}$ Organization, Information and Learning Sciences Program, University of New Mexico, Albuquerque, USA \\ ${ }^{2}$ School of Business Administration, Portland State University, Portland, USA \\ ${ }^{3}$ Anderson Schools of Management, University of New Mexico, Albuquerque, USA
}

\begin{abstract}
This study analyzes the challenges faced by struggling or low-growth economies when they lose highly skilled human capital via the process of "brain drain" or "ability drain." Such losses pose severe potential hazards to technologybased economic development. Factors related to these phenomena are characterized and examined via literature review and mixed methodology analysis to compare and contrast potential ways to manage brain drain and even achieve positive "brain gain" through individual and business-oriented strategies and policy alternatives.
\end{abstract}

\section{INTRODUCTION}

New Mexico faces many challenges as it pursues a path toward greater economic development for the state as a whole. Technology is considered a key factor in economic development, which is in turn is dependent upon both a welleducated populace and a well-functioning business environment [1]. One of the big challenges for New Mexico, as a rural, and low population state is ensuring that it will have enough highly skilled and educated professionals to keep its businesses and institutions functioning on a necessary level. New Mexico is currently experiencing the loss of tens of thousands of skilled professionals every year and record low enrollment in its colleges and universities despite fairly generous state- subsidized tuition. The loss of highly skilled and educated "human capital" from one region to another [2] is often referred to as "brain drain" [3] or "ability drain" [4]. The problem of brain-drain has become a vexing challenge for developing economies like New Mexico. In addition to investments in education, the state has spent considerable time and financial resources in efforts to attract new businesses and industries and is attempting to grow its entrepreneurial base. Such government policies are another factor often considered important for technology-based economic development [5]. However, thus far, none of the state interventions has significantly stemmed the losses. Therefore, this research aims to investigate the nature of this problem and to explore some possible future directions for solutions to this problem.

We examine several potential interventions to retain skilled professionals. We believe that the state can offer remission on licensing and testing fees for different professions which we want to encourage to remain in the state, such as doctors, lawyers, engineers, technology entrepreneurs, public safety officers, and teachers, in particular. We believe that also offering to cover expenses for business permits and business registration can likewise encourage businesses to form here and remain, especially if they can get access to free business advice and perhaps limited information technology support.

More importantly, we can modify the existing Legislative Lottery Scholarship program so that requires students to remain in the state after graduation and is more targeted about which fields of study it finances. Given the centrality of education in New Mexico's economy, the state should do everything possible to ensure that New Mexicans gain access higher education, business skills, and entrepreneurial experience. More importantly, once New Mexicans develop high-value skills and know-how, the state should strive to keep them in New Mexico, where they can grow and benefit the local economy.

\section{BACKGROUND}

New Mexico has a problem producing, keeping, and attracting talented workers. In the first case, a Board of Regents member from the state's flagship institution, the University of New Mexico (UNM), was quoted as claiming, "We don't have a good product: $50 \%$ of our customers get nothing of value they can show" [6]. While these claims were quickly disputed, the fact remains that New Mexico only has a $71 \%$ high school graduation rate overall [7] along with a $14 \%$ on-time bachelor's degree graduation rate [8], placing it 49th in the nation on that metric. This, along with a host of other bottom-of-the-barrel statistics, such as 49th in the nation for unemployment rate [9], worst in the nation for child poverty rate, at the $30 \%$ mark, and worst in the nation burglary and robbery rate [10] indicate that New Mexico has some serious challenges to overcome.

To be sure, these problems exist for a variety of multifaceted reasons. For example, the American Society of Civil Engineers rate New Mexico's Infrastructure at the D+ level, citing a "capital expenditure gap of \$407 million," along with 167 dams "considered to be high-hazard potential," and $\$ 1.5$ billion in drinking water or waste water improvement needs [11]. This combines with a lack of cultural amenities, such as a relative dearth of professional sports teams outside 
of the Triple-A rated minor league Albuquerque Isotopes [12] and occasional upstarts like the Duke City Gladiators [13]

While perhaps New Mexico can be forgiven to a degree in terms of some of its relative rankings, having only become a state in 1912 [14], the fact remains that all of this in total makes it difficult for New Mexico businesses to compete for the most talented labor in terms of wages or living conditions or to keep homegrown talent. Thus, low-ranked states can remained locked in self-reinforcing viscious cycles, where poverty and brain-drain begets more poverty and brain-drain. The state needs to stop making excuses for past failures and find ways to create virtuous cycles of increasing wealth and brain-gain. New Mexico's relatively recent statehood hardly works as a plausible argument for its low rankings, given that Arizona was admitted the same year and has over three times the Annual Gross Domestic Product [15]

\section{A. Economic Development Successes and Failures}

New Mexico has had some limited amount of success in attracting big companies, including the Los Lunas Facebook Data Center [16], Moriarty's Google affiliated Titan Aerospace d.b.a SkyBender [17], Spaceport America, Netflix's bargain acquisition of ABQ Studios [18], and a slew of smaller but vital companies including Top Golf / Big Shots [19], Safelite [20], Keter Plastics [21], and Union Pacific [22], among other notable achievements.

It is also worth noting that, while New Mexico is able to "poach" some of these businesses from nearby states, often at the expense of enormous packages of tax breaks and other economic incentives, these victories are often short-lived since other states tend to poach businesses and employees back from New Mexico as well.

Indeed, New Mexico has also had some notable losses of businesses such as Eclipse Aviation [23] and later the merged Kestral/ONE Aviation [24]. Overall, however, it is fairly accurate to say that the state has made strides toward diversifying its economy [25] away from complete reliance on more traditional extractive industries, like oil, gas, coal, and mining [26]. Still, New Mexico's state government budget projections, while less dependent on these fossil fuel industries than at times in the past, still fluctuate wildly between shortfall and windfall depending upon the price of oil on the world markets and the cycle of busts and more recently booms produced by exploration [27].

Additionally, New Mexico has a difficult time escaping from its reliance on federal government spending by the Department of Defense and the Department of Energy. New Mexico gets $\$ 3.1$ billion annually [28] from its four military bases, Kirtland Airforce Base, Cannon Airforce Base, Holloman Airforce Base, and the largest of them all geographically, White Sands Missile Range [29].

One of the ways that New Mexico has lessened this dependence is with development programs that provide financial resources to attract new business. New Mexico's Job Training Incentive Program (JTIP) is extremely generous, reimbursing $50-75 \%$ of employee wages for up to six months to accommodate businesses that expand or relocate [30]. Add to this the Local Economic Development Act or LEDA grants to help communities attract business [31], and the Catalyst Fund for providing seed funds to innovative startups [32], and it would seems that New Mexico is not without tools to grow its economy.

New Mexico also has no shortage of business incubators, business accelerators, and venture capital funds chasing the latest home run of successful startup companies [33]. Of course, if such companies survive, they must also be cultivated and encouraged to stay in the state. Lavu [34], Descartes Labs [35], and USA Beef [36] are some notable success stories.

However, it is worth noting that startup companies in general, do not always have the best track record for long-term survival, with somewhere between $60 \%$ to $90 \%$ of startups not surviving past 10 years [37]. More often than not, the startup companies that emerge from business incubators, if they are viable at all, yield solo-preneurs, or one-person companies [38]. Start-ups, however, are still a relatively recent addition to New Mexico's efforts to diversify its economic ecosystem and hit new homeruns in the business arena.

An area that is demonstrably a homerun is New Mexico's emerging film industry. Starting in 2002, Governor Gary Johnson signed legislation providing incentives for film production in tax credits [39]. Since that time, these tax credits-while being somewhat complex in formulation and topping out at $30 \%$ of production costs--have contributed an estimated $\$ 1.5$ billion to the New Mexico economy between 2010 and 2014 alone. They are also credited with creating 15,848 full-time jobs, and at least 43 cents per dollar of state tax revenue for the $\$ 251$ million that the incentives cost [40]. They have also created $\$ 104$ million in local tax revenues. More recently, Netflix acquired ABQ Studios as a production hub and reported plans to spend upwards of $\$ 1$ billion on production alone over the next ten years [41]. Although some have questioned the deal that allowed Netflix to acquire the studio--which cost $\$ 91$ million to build--for the bargain price of $\$ 30$ million [18], it is believed that this deal alone will create 1,000 new jobs and generate substantial tax revenues, as well as economic multiplier effects [42].

Of course, not everyone believes that film industry tax credits are ultimately a good bet for New Mexico. The state competes with at least 31 other states which also have a variety of film incentive programs and tax breaks [43]. Competition also comes from a variety of other countries, from Canada to India, where labor and production costs may ultimately be lower. Thus, some worry this strategy may ultimately end up being a race to the bottom [44]. In the short term, however, there is little doubt that New Mexico has reaped net rewards from this industry, and could likely do far more in term of developing additional studio space, back lot sets, and post-production facilities in the state.

An area of economic development far outside the state's traditional core industries has been in the development of Space Port America [45]. Billionarie Richard Branson famously located his space tourism business, Virgin Galatic, at Spaceport America. However, to date, the results have been decidedly mixed. Billing itself as "the world's first purpose built commercial spaceport," it is situated on 18,000 acres of 
land near Truth or Consequences, NM. It also has also obtained 6,000 square miles of restricted airspace, and boasts more than 340 clear days per year, which is a critical resource for launches of emerging rocket companies which would make use this facility. But, after $\$ 220$ million in public funds invested since groundbreaking in 2006, neither Doña Ana or Sierra County have much to show from the project in terms of tax receipts.

\section{B. The Enduring Problem}

Unfortunately even with economic growth returning after a decade of recession, New Mexico is experiencing a net population loss, with tens of thousands of mainly younger citizens fleeing to greener pastures in Colorado and Texas [46]. While at one time New Mexico had one of the fastest growing economies in the nation, now it has one of the slowest [47]. This can, in turn, create a downward spiral, worsening the prospects of gaining or retaining businesses and highly skilled workers. This is part of the problem commonly referred to as brain-drain, although the term itself has a variety of definitions.

Given the generally recognized importance of education for individual economic success [48], and the impact that education can have on the success of state and local economies [49], the loss of highly skilled and educated "human capital" [2] has traditionally be an area of concern for economists [50]. The phenomenon of "brain drain" [3] or more generally "ability drain" [4] has been a recognized problem for many decades. The phenomenon is often associated with developing countries [51], but also occurs within the United States, particularly for highly trained individuals, like physicians, located in state developing economies [52].

New Mexico, like many states struggling with economic development, has become emblematic of the brain-drain challenge, especially given persistently elevated unemployment rates [26]. This problem has remained despite ostensible efforts at investment in public education. In fact, some researchers describe the brain-drain process as "subsidizing the competition," and say that it is something that smaller and more rural states have been experiencing for a long time [53]. Essentially, these states often go through considerable expense to try to educate their populations and bring their citizens out of poverty, only to find that once people gain advanced educations, they prefer to leave these states and pursue better opportunities elsewhere. According to Department of Dducation figures, New Mexico has lost 42,000 individuals between 2011 and 2016, 17,000 of whom have bachelor's degrees or higher. The evidence suggests that highly skilled individuals are attracted to leave, after completing training for the greener pastures of higher paid jobs in better labor markets [54]. On the one hand, it is a perfectly reasonable decision for individuals to seek the best opportunities available. In order for highly educated professionals to stay in an area, there need to be sufficient opportunities to support them and the quality of life that they desire. But, on the other hand, it is disheartening to think that supporting education could actually be hastening the flight of the newly educated. Therefore, a primary motivation of this research is to consider how to invest in not only education, but to encourage the kind of local economic development and quality of life amenities that make a place an attractive location where locally educated people will want to stay and even for people from outside areas to want to relocate.

\section{Current Responses or Interventions}

One potential avenue to respond to the loss of highly educated New Mexicans is through the use of scholarships. Rather than losing the brightest High School graduates to prestiguous schools in other states, scholarships can help incentive high-achieving students to attend local colleges and universities. There is evidence that this has worked in other states as a means of retaining High School graduates who may also start families, and potentially enter the workforce in the local area. Missouri, for example, has, for several decades, implemented a targeted, merit-based scholarship program called the Bright Flight Scholarship Program [55], which has demonstrated some success in retaining students up to eight years after high school graduation [56].

Notably, however, only the top 3\% of Missouri High School graduates, based on SAT/ACT scores, are even able to qualify initially for the Bright Flight program. They also must be full-time students, along with a number of additional restrictions, that make it of limited use to wider swathes of the population. Furthermore, these students receive a maximum award of $\$ 3,000$, and in some cases only $\$ 1,000$, which is unlikely to be enough to really retain the best and brightest of students. In fact, ample criticism exists for this particular scholarship program which was established almost 30 years ago and is believed to exclude many minority and rural students who tend to have lower standardized test scores [57].

The state of New Mexico currently has its own Legislative Lottery Scholarship Program [58] based partially upon academic merit. Versions of this program have existed since the 1990's, but an updated version discussed here came into effect in 2016 [59]. The requirements are notable less stringent than those of Missouri, and cover tuition of up to $\$ 2,294$ per semester at the University of New Mexico, for example [60]. However, to become eligible for this, students must first complete a qualifying semester in which they earn 15 credits in college coursework with a minimum 2.5 grade point average.

To accomplish this, most New Mexico High School graduates wanting to attend a state college will first apply for a New Mexico Bridge Scholarship, which covers their first semester of tuition. However, this funding is on a first come, first serve basis, with more limited availability than the Legislative Lottery Scholarship, and often has school-specific restrictions. Central New Mexico Community College (CNM), for example, has a Bridge To Success scholarship, which requires that High School students attend the fall semester directly after graduating from a New Mexico High School or GED program and be eligible for all other requirements to receive a New Mexico Legislative Lottery Scholarship [61]. The Bridge scholarship, however, only covers the actual cost of tuition and registration but not additional common class fees and books, which must be supplemented separately. 
New Mexico also have a variety of other grant and scholarship programs, such as the New Mexico Scholars Program [62] for high achieving students. However, none of these have any component that specifically articulates the goal of retention of students in the workforce after college graduation. At most, there is an implicit assumption that students will likely attend school here, perhaps start a family, get a house, and stay.

Unfortunately, it is not clear that this is what is happening with the roughly 26,000 New Mexico students who receive these funds each year. Rather, despite increasing their funding levels, the state has seen fewer students even applying for the scholarship and New Mexico state schools are facing the highest enrollment losses in the nation on a percentage basis, tied with those of Louisiana [63]. This is despite the fact that Louisiana also has a very similar, though in some ways slightly less generous, state-subsidized scholarship program called the Taylor Opportunity Program for Students [64] or TOPS scholarship, which started around the same time as New Mexico's Lottery Scholarship program.

So, there is no conclusive evidence that these programs are having positive retention effects, as they have in Missouri. In fact, most currently available evidence suggests that there are still sizeable losses, even with fairly significant amounts of government spending to help students obtain an advanced education. While it is possible that the plans are not generous enough or that they might be adjusted to be more competitive, it appears that this approach in general has a somewhat questionable ability to retain students, at least on its own. Some additional set of factors would appear to be necessary in order to keep graduates and professionals in the state.

As already noted, New Mexico already has a considerable number of business incubators, accelerators, and similar entrepreneurial jumpstarting initiatives, which, despite the slight distinctions which exist between these various different approaches, we will generically refer to as incubators. Traditionally, these incubators have been a strategy to staunch rampant brain-drain, especially in the developing world [65]. While New Mexico is certainly not identical with the developing world, it is a low-growth and under-developed US state, and as such, we can expect that some of the insights obtained from these other countries would have a degree of transferability, even if they cannot be completely generalized.

Our universities in particular are leading the way in terms of entrepreneurship. UNM, for example, has started an Innovation Academy nd Lobo Rainforest [66], which is part of an immersive business student training program at the Anderson School of Management, where students live and work and participate in business pitch competitions on a regular basis. Other universities have similar programs such as New Mexico State University's Arrowhead Center Technology Incubator [67], which focuses somewhat more narrowly on "Water, Energy, Agriculture Nexus" and "Digital Health". This is a promising approach that capitalizes on New Mexico's natural resources, not using the traditional extractive resource model the state has historically relied upon, but by harnessing $21^{\text {st }}$ century thinking about developing a market case for green energy and natural resources [68]. However, while this trend is important, the future economic development that may results from such technologies depends upon an uncertain evolution of social values, which will determine how much the market adopts such technologies, as well as how many people gain the skills and education levels necessary to drive these emerging industries [69].

Other publically funded incubators include ABQid [70], sponsored by the City of Albuquerque, and CNM's STEMulus Center [71]. All told, there are at least a dozen business incubators or accelerators in New Mexico with New Mexico Economic Development Division certification [32].

Depending upon the individual or group to whom you talk, these various projects each have their share moderate successes, along with a lot of less successful participants. Perhaps, in all fairness, these initiatives have not been given sufficient time to bear fruit and there is reason to be cautiously optimistic about future results. However, such results assume a reasonably well-funded and sustained effort can be made to move people through this pipeline and to strategically ensure that those who can be successful are committed to remaining in the state.

\section{DISCUSSION \& RECOMMENDATIONS}

What is becoming increasingly clear from the picture so far is that for low-growth states like New Mexico, all of the present efforts still do not seem sufficient in order to stem the tide of job losses, even at a time when our nation is actually experiencing booms in the levels of employment and new job creation exceeding the number of individuals unemployed [72].

Of course, this does not always trickle down to individual state economies. Instead, what may be necessary is a consideration of how specific policies can be crafted to target parts of New Mexico's economy where the state particularly wants to retain people. For example, it would almost certainly like to retain the most highly-educated, licensed professionals, such as doctors, lawyers, nurses, professional engineers, teachers, and similar categories of individuals required to be licensed with the State of New Mexico Regulation and Licensing Department [73]. Many of these individuals are often the product of New Mexico schools and have acquired critical abilities which we need in the state to function and develop.

\section{A. Professional Licensing}

Given the above arguments that these individuals are critical to the economy of the state and might otherwise leave it for greener pastures, one possible initiative which could be researched would be offering remission of licensing fees, at least on a first time basis, as an overture to attempt to encourage these professionals to stay in the state. The idea here would be that, while there would certainly be a loss of revenue associated with initial forgiveness of fees, the licensee would have to stay within the state to benefit from the license. While in the state, these individuals would presumably start businesses or get jobs in their profession with the use of the initial license and therefore pay sales and income taxes, as well as possible property taxes if they acquired homes. This would, in essence, be a way to grab professionals one last time 
before they left the state and offer them a tangible reason, even if only a token, to encourage them to stay. It is not clear that such a scheme would work, which is why research would be required. Future research could include attitude surveys, for example, to determine the likelihood that such incentives would have a positive effect on retention. This information could then be used to create a trial program for reducing braindrain.

\section{B. Business Assistance}

In addition to providing remission on licensing fees, which is admittedly often a rather small cost when prorated over several years, it would be possible to provide other forms of assistance to these professions, especially in terms of helping to start a business. Helping with and covering many of the standard costs associated with starting businesses, such as paying for business permits, and providing assistance and covering fees for incorporating a business in New Mexico would be examples of such an approach.

By providing at least some level of assistance to individuals both in the start-up community and also to targeted professions, such as doctors or engineers, for example, this would show a level of commitment to retaining them in the state and perhaps local community. Individual businesses often think of ways to retain their best employees, so it certainly makes sense for the state to think in similar terms about the level of support that it could reasonably afford to provide to business professionals. Organizations like New Mexico Partnership already exist to assist businesses looking to relocate to the state and having a similar service that sought to retain those wishing to stay in the state would be an easy extension [74].

This is an areas where we would again recommend future research before offering a series of possibly expensive but unnecessary or underutilized resources. For example, many start-up business working within the business incubator or accelerator frameworks have access to things like legal advice, office space, and even IT support. However, in many cases, these resources are not well utilized and are only actually utilized by a tiny segment of the business population [75] Before attempting to implement such a program on a large scale, a study of what resources were considered most desirable by these professionals would clearly be justified.

\section{Housing Assistance}

It is possible that other similar incentives may also be targeted toward select groups of professionals that one might want to retain in the state. The Teacher Next Door program is an example of a national home buying program that provides some grants or down payment assistance to teachers to help them buy homes in a particular area [76]. There are similar programs called Officer Next Door, Nurse Next Door, or Firefighter Next Door. If the state of New Mexico is serious about addressing brain-drain, particularly in a set of targeted skill areas, then potentially modeling a similar program and expanding it to other desired professions would also make sense. Clearly assisting with a home purchase, if it could be done in a reasonably affordable way by the state, would have the potential to create a property tax base to compensate for the initial cost of the program, and in some ways, would be similar to the deals that are offered to larger corporations whom the state is attempting to attract.

\section{Targeted Scholarship Policy Modification}

A final alternative that we recommend the state consider would be some modifications to the already rather complex and expensive scholarship program which exists in the form of the Legislative Lottery and Scholars programs. As presently configured, these scholarship funds do not devote specific monies to particular industries which might be considered a priority for the state. Given the many industries which are presently on the rise in New Mexico, targeting additional funding from the Legislative Lottery Scholarship toward specific fields like Film Production, entrepreneurship training programs, or those in areas like the professional licensure areas already mentioned, might be a way to make better strategic use of funds. In certain state programs, there are specific fields, such as degrees in theology or doctorates in divinity, which are specifically excluded from the program. So, this is another potential route that one could go in terms of discouraging New Mexicans from studying in low-demand areas. Right now, there is not any specific attempt to incentivize things like the graduation of substantially more police officers, for example, as a means of addressing or high crime rates, or graduating more teachers to address the state's chronic K-12 teacher shortages.

More generally, the Legislative Lottery scholarship might make requirements of all recipients of funding in terms of staying in New Mexico. While it would likely be difficult to enforce, asking for those graduating with associate degrees to remain in the state for one year after graduation and those graduating with bachelor's degrees to stay in the state to stay for two years beyond graduation might not be unreasonable. Again, this is an area that would have to be studied. Clearly, people who wanted to stay in the state after graduation would need to be able to support themselves, and if the job market was simply not available to employ them, then allowances would have to be made.

So, any mandates about graduates staying or being forced to pay back funds if they left prematurely would have to be carefully considered. However, it seems reasonable that a study could identify some of those career areas, such as public safety officers or teachers, who could possibly even be guaranteed jobs in our perennially short-staffed communities upon graduation. A program of this nature would be accomplishing precisely what we have described in terms of preventing those trained in the state from needing to go to the considerable expense and trouble of relocating, while addressing pressing community needs. Such a program might even achieve a measure of brain-gain, in which individuals from out of state might be attracted by the prospect of a guaranteed job placement as a police service aid, or a teacher, for example, so long as these individuals completed requirements at New Mexico schools. While it is possible that such a program would be expensive, and would have to be appropriately researched in terms of potential cost, it is not out of line with what the state already does in programs like JTIP, which we previously noted pays for as much as $75 \%$ of 
employee wages for up to six months of training for businesses that are relocating to the state.

\section{RESUlts}

Given the fairly wide variety of possible interventions which have been explored there clearly needs to be some comparative analysis of what it would take to implement these programs. This includes a consideration of financial and time resources which might be required to make these interventions happen.

\section{A. Analysis of Alternatives}

Of the strategies explored so far, subsiding professional licensing, in a relative sense would seem to be one of the cheapest. As just one example, the initial licensing to take the exam to practice as a Dentist in New Mexico is $\$ 600$, with a 1 year temporary license fee of $\$ 400$ [73]; the cost to be licensed as a Dental Hygenist is $\$ 250$ per year; and a Dental Assistant license is $\$ 50$ per year. These are indicative to the range of fees that are charged for many professional licenses. So, the cost to help retain 1,000 dental assistants in New Mexico would be $\$ 50,000$, whereas keeping 1,000 Dental Hygenists would increase to $\$ 250,000$, and the cost to keep the same number of dentists would \$1 million.

Of course, there are actually only 866 general dentists in the entire state and only a handful of these are new dentists who are just getting their initial license [77]. If we roughly estimate that we are mainly spending money on the lower and middle tiers of the profession, we could probably allocate $\$ 500,000$ for each of ten targeted professions and still have a relatively modest for reducing professional brain-drain that only needed appropriations of around $\$ 5$ million, plus administration and overhead costs for the program. This would still be a fairly modest state program, even by New Mexico standards.

However, on the benefits side, Dentists earn yearly salaries of around \$ 167,650 in New Mexico and Dental Hygenists earn $\$ 71,970$. Similarly, registered nurses earn about $\$ 70,000$ and pharmacists make $\$ 118,000$ [78]. So, keeping more of these professionals in the state is certainly going to pay dividends far beyond initial licensure costs.

The cost of a policy initiative to help individuals with down payments for home loans or the cost of providing business support would certainly be comparatively more expensive. The most expensive option, of course is making extensive changes to the scholarship programs like the Legislative Lottery Scholarship, which currently spends in the neighborhood of $\$ 40$ million annually [79]. However, for what it is worth, these programs already both exist, and would simply have to be modified in order to set some priorities. Theoretically, the Legislative Lottery Scholarship could ask students to commit to working in New Mexico as a condition of accepting funding with no additional cost in expenditures. For that matter, excluding certain fields of study from funding, perhaps based upon an economic study of the least likely professionals to remain in the state would not necessarily cost much either. However, if they resulted in greater retention of even $10 \%$ of the current college graduates that are being lost then the benefits would dwarf the costs.

Similarly, people in certain professions can already benefit from home-buying assistance programs. The question would simply be how much would be appropriate for the state to do in terms of expanding these programs to target other specific groups of professionals. Many of these programs receive subsidies through federal programs like HUD, so it would not necessarily cost the state a lot of money to supplement these programs.

Even in the case of placing graduates in targeted fields, such as public safety and teachers, into guaranteed jobs, these jobs are in such high demand that the service being provided would essentially be one of maintaining a job bank. The state would not be responsible for subsidizing salaries, though we have already noted that they are supposedly prepared to do so in the case of programs like JTIP.

Perhaps, then, the interventions where more expense would be involved would be in providing business support and even IT assistance to professionals starting businesses. Again, covering the costs of things like business permits, or incorporation fees would not be a major expense. Given that over a dozen business incubators already exist in the state, expanding their staffing and resources to help then serve more people would add to their incremental costs, but such programs would not need to be built from scratch. Therefore, the support needs would only be an additional percentage of what is already budgeted. In the final analysis, the cost of losing highly educated, skilled, and productive workers by the tens of thousands each year is almost certainly more than the cost of the interventions.

\section{CONCLUSIONS, Limitations \& FUTURE WORK}

Given the reality and the severity of the problem of braindrain to developing economies, like that of New Mexico, a better understanding of the driving factors, the impact, and the potential solutions is essential moving forward. The primary goal of this initial research was to review existing literature and characterize the nature of the challenge. The research also made a first attempt to identify potential strategies and alternative that could be reasonable for tackle this issue moving forward. This is ultimately a complex topic that defies easy solutions and will almost certainly require more detailed research efforts in order to design an effective intervention plan that has a reasonable chance of success. We hope this work has helped frame the initial strategic landscape, provided some general guidance on approaches that may be effective based upon what other states and even what other countries have been doing to address similar challenges affecting their own development, and proposed some avenues for future research. Policy makers, technologists, and economic development professional reading this work can use it to inform discussions about the nature of the brain drain challenge in low-growth economies, like New Mexico. Furthermore, we have identified a number of potential steps that might be taken to begin mitigating such problems. Any future work, however, would have to be predicated upon additional detailed research on 
specific conditions, goals, and the likelihood that specific interventions would lead to specific level of outcome.

Given the focus that most of this study placed upon specific economic challenges of New Mexico, this study cannot guarantee to produce generalizable results or strategies for other states, countries, or developing regions. However, there is likely to be a degree of transferability between the lessons learned by the challenges in one developing economy and another. It is also worth noting that some of the strategies discussed here are rather generic in terms of public policy approaches. There is little certainty how they might function in a much different economic setting, or in a more developed economic ecosystem, driven by a different mix of business and government conditions. However, we feel that it would be valuable to attempt to apply our analysis to a variety of different contexts in order to contribute to knowledge in the field.

As alluded to earlier, we believe that finding the specific set of program interventions that would be most effective in preventing brain-drain is something that should ultimately be done as mixed-method research, employing quantitative, quasiexperimental, and qualitative techniques that allowed a deepened understanding of the phenomenon in general. In this way, we could test the various different proposals to see which ones are most effective in more limited field trials before attempting these approaches on a wide scale. Getting feedback from the individuals being targeted in terms of what they wanted or would find most helpful is the likely to be very useful in crafting a set of incentives that we can use to retain talented professionals. Therefore, it is hoped that work like this could form the basis for a additional research project that could lead to strategies and policy alternative to solve the challenging problem of brain-drain.

\section{REFERENCES}

[1] H.-J. Steenhuis and E. J. Bruijn, "Technology and Economic Development: a literature review," International Journal of Innovation and Technology Management, vol. 09, p. 1250033, 2012.

[2] G. S. Becker. (1964). Human Capital : A Theoretical Analysis. Available: http://www.myilibrary.com?id=206955\&ref=toc

[3] J. N. Bhagwati and K. Hamada, The brain drain, international integration of markets for professionals and unemployment; a theoretical analysis. [Cambridge]: [M.I.T.], 1973.

[4] M. Schiff and C. Robert Schuman, Ability drain, 2015.

[5] K. R. Cowan, "'Technology Planning for Aligning Emerging Business Models and Regulatory Structures: the Case of Electric Vehicle Charging and the Smart Grid"," PhD, Engineering \& Technology Management, Portland State University, PDXScholar, 2107.

[6] J. Dyer, "Regent's comments about UNM not offering a 'good product' draw fire," in Albuquerque Journal, ed, 2018.

[7] NMDOH. New Mexico's Indicator-Based Information System [Online].

[8] R. Nott, "Just 14\% of New Mexico's college students graduate on time," The New Mexican, December 7, 2017.

[9] A. Oxford, "NM unemployment drops but still among nation's highest rates," in The New Mexican, ed. Santa Fe, NM, 2018.

[10] AP, "New Mexico ranks among most dangerous states in the country," ed: Associated Press, 2015.

[11] ASCE, "New Mexico Infrastructure Overview," American Society of Civil Engineers, 2018.

[12] B. America. (2018). Albuquerque Isotopes. Available: https:/www.baseballamerica.com/teams/3016/albuquerque-isotopes/

[13] D. C. Gladiators. (2018). Duke City Gladiators. Available: http://www.dukecitygladiators.com/
[14] USNA. (2012). New Mexico and Arizona Statehood Anniversary Available: $\quad$ https://www.archives.gov/legislative/features/nm-azstatehood

[15] C. Economy. (2017). U.S. states comparison: Arizona vs New Mexico. Available: https://countryeconomy.com/countries/usastates/compare/arizona/new-mexico

[16] C. Ortiz, "Report spotlights the economic impact of Facebook's data centers," ed, 2018.

[17] M. English, "Google pulled Titan Aerospace out of New Mexico, right? Not so fast," ed, 2016.

[18] T. Spangler, "Netflix Is Paying Less Than \$30 Million for Albuquerque Studios, Which Cost \$91 Million to Build," in Variety, ed, 2018.

[19] S. Soliz, "Two companies plan golf facilities in Albuquerque," ed: KOB, 2018.

[20] Safelite. (February 10, 2017). Safelite AutoGlass' New Rio Rancho Contact Center Now Open. Available: https://www.safelite.com/aboutsafelite/press-releases/safelite-autoglass-new-rio-rancho-contact-centernow-open

[21] J. Dedinger. (November 1, 2017). Keter Plastics to soon begin manufacturing. Available: http://www.news-bulletin.com/news/keterplastics-to-soon-begin-manufacturing/article a87b686c-bf22-11e7b068-47228cde9332.html

[22] A. Staff, "Union Pacific Hopes To Move Rail Hub From El Paso to Santa Teresa," in Albuquerque Journal, ed. Albuquerque, NM, 2011.

[23] Finrock. (2018). Eclipse Reaches Settlement To Continue Operating at $A B Q$. Available: $\quad$ www.ainonline.com: https://www.ainonline.com/aviation-news/business-aviation/2018-0614/eclipse-reaches-settlement-continue-operating-abq

[24] J. Lyon. (2018). Very Light Jet Pioneer One Aviation Augers In (Again). Available: https://robbreport.com/motors/aviation/one-aviation-eclipsechapter-11-bankruptcy-2822360/

[25] M. Geisel, "NM's huge strides toward healthier economy," in ABQJournal, ed, 2018.

[26] NMDWS, "New Mexico 2017 State of the Workforce Report A Report Highlighting New Mexico's Current and Future Workforce," New Mexico Department of Workforce Solutions, 2017.

[27] D. Boyd, "Oil boom drives NM revenues to record high," in ABQJournal, ed. Albuquerque, NM, 2018.

[28] NCSL, "Military Impacts on State Economies," National Conference of State Legislatures, 2018.

[29] T. Kurtz. (2015). A look at new mexico's military bases. Available: https://www.koat.com/article/a-look-at-new-mexicos-militarybases/4480481

[30] NMT. (2018). New Mexico True: Job Training Incentive Program. Available: https://gonm.biz/business-development/edd-programs-forbusiness/job-training-incentive-program/

[31] NMT. (2018). LEDA FY18 Program Summary. Available: https://gonm.biz/business-development/edd-programs-forbusiness/finance-development/leda

[32] NMT. (2018). New Mexico Catalyst Fund. Available: https://gonm.biz/business-development/edd-programs-forbusiness/office-of-science-technology/new-mexico-catalyst-fund

[33] NMTechworks. (2018). Business incubators and accelerators. Available: http://www.nmtechworks.com/business-incubators.html

[34] Lavu. (2018). About Lavu. Available: https://www.lavu.com/about-lavu

[35] Descartes. (2018). About Descartes Labs. Available: http://www.descarteslabs.com/about.html

[36] UBP. (2018). About Us. Available: http://www.usabeefpacking.com/

[37] E. Griffith. (June 25, 2017) Conventional Wisdom Says 90\% of Startups Fail. Data Says Otherwise. Fortune. Available: www.fortune.com: http://fortune.com/2017/06/27/startup-advice-data-failure/

[38] J. Rampton. (May 15, 2015) 4 Differences Between Solopreneurs and an Entrepreneur Working Alone. Entrepreneur. Available: https://www.entrepreneur.com/article/245766

[39] Pop and Peach. (2018). The Film Industry in New Mexico and The Provision of Tax Incentives. Available: http://arrowheadcenter.nmsu.edu/wpcontent/uploads/2015/06/filmindustryfinal.pdf

[40] D. Boyd, "New Mexico film impact estimated at $\$ 1.5$ billion," in ABQJournal, ed. Albuquerque, NM, 2014.

[41] C. O'Falt, "Netflix Buys New Mexico Production Hub: Why Hollywood Is Sinking Billions Into Albuquerque," ed: Indiewire, 2018. 
[42] R. Davis, "Behind the deal for Netflix to invest \$1B in New Mexico," in bizjournals, ed, 2018.

[43] NCSL, "State Film Production Incentives and Programs," National Conference of State Legislatures2018.

[44] M. Geist, "Tax credits for film and TV production a race to the bottom," ed, 2015.

[45] Spaceport. (2018). About Us. Available: https://spaceportamerica.com/

[46] A. Oxford, "New Mexico is growing even as residents move away," in The New Mexican, ed. Santa Fe, NM, 2018.

[47] G. Galvin, "New Mexico's Exodus Problem," in U.S. News, ed.

[48] C. Jencks and S. Bartlett, Who gets ahead? The determinants of economic success in America. New York: Basic Books, 1979.

[49] W. M. Bowen and H. Qian, "State spending for higher education: Does it improve economic performance?," RSP3 Regional Science Policy \& Practice, vol. 9, pp. 7-23, 2017.

[50] O. Galor and D. Tsiddon, "The Distribution of Human Capital and Economic Growth," Journal of Economic Growth vol. 2, pp. 93-124, 1997.

[51] F. Docquier, O. Lohest, and A. Marfouk. (2007). Brain Drain in Developing Countries. Available: http://hdl.handle.net/10986/4454

[52] G. Brock and M. Blake, "What should be done to address losses associated with 'medical brain drain'?," Journal of medical ethics, vol. 43, pp. 558-559, 2017.

[53] S. Soliz, "Vote 4 NM: Brain Drain appears to be costing the state," ed: KOB, 2018.

[54] NCES, "Digest of Educational Statistics," National Center for Education Statistics, 2016.

[55] MDHE, "Bright Flight Program," Missouri Department of Higher Education, 2018.

[56] J. R. Harrington, J. Munoz, B. R. Curs, and M. Ehlert, "Examining the Impact of a Highly Targeted State Administered Merit Aid Program on Brain Drain: Evidence from a Regression Discontinuity Analysis of Missouri's Bright Flight Program," Research in Higher Education, vol. 57, pp. 423-447, 2016

[57] A. Overton and K. Anderson. (2016). Inherent Inequities: How Missouri's BrightFlight Scholarship Program Fails Key Demographics. Available:

https://www.sfstl.org/sites/default/files/files/Bright $\% 20$ Flight $\% 20$ Materi als.pdf

[58] NMDHE. Legislative Lottery Scholarship Program [Online]. Available: http://www.hed.state.nm.us/students/lotteryscholarship.aspx

[59] NML. Legislative Lottery Scholarship Update [Online]. Available: https://www.nmlegis.gov/handouts/ALESC $\% 20092415 \% 20$ Item $\% 2011$ $\% 20$ Legislative $\% 20$ Lottery $\% 20$ Scholarship $\% 20$ Update $\% 20$ (Fact $\% 20$ Sh eet).pdf

[60] UNM. Legislative Lottery Scholarship [Online]. Available: http://scholarships.unm.edu/Resources/lottery-scholarships.html
[61] CNM. Bridge to Success Scholarship [Online]. Available: https://www.cnm.edu/depts/financialaid/scholarships/documents/bridge-scholarship-factsheet.pdf

[62] NMDHE. New Mexico Scholars Program [Online]. Available: http://www.hed.state.nm.us/students/nmscholars.aspx

[63] J. Dyer, "NM lottery scholarships to get big increase," in Albuquerque Journal, ed, 2018

[64] PFTF. Taylor Plan [Online]. Available: http://www.taylorplan.com/resources/louisiana-tops/

[65] F. Deitrich. (2018). Stopping the "Brain Drain" in Developing and Emerging Nations. Available: http://www.digital-developmentdebates.org/issue-06-innovation--business--stopping-the-brain-drain-indeveloping-and-emerging-nations.html

[66] UNMSTC. (2017). Building a Rainforest In The Desert. Available: https://stc.unm.edu/wp-content/uploads/2015/06/Fall-2017-FINAL-eversion.pdf

[67] NMSU. (2018). Arrowhead Center. Available: http://arrowheadcenter.nmsu.edu/technology-incubation/

[68] K. R. Cowan and R. R. Harmon, "The Market Case for Green Energy: A Multiple Perspectives Approach," in PICMET '07 - 2007 Portland International Conference on Management of Engineering \& Technology, 2007, pp. 2498-2508.

[69] K. R. Cowan, T. Daim, W. Wakeland, H. Fallah, G. Sheble, L. Lutzenhiser, et al., "Forecasting the adoption of emerging energy technologies: Managing climate change and evolving social values," in PICMET '09 - 2009 Portland International Conference on Management of Engineering \& Technology, 2009, pp. 3048-3058.

[70] ABQid. (2017). ABQid Identifying Developing Start-ups. Available: https://www.abqid.com/about-abqid/

[71] CNM. (2017). CNM STEMulus Center. Available: https://stemuluscenter.org/

[72] J. Bartash, "U.S. job openings hit a record 7.1 million, exceed number of unemployed Americans," in Marketwatch, ed, 2018.

[73] NMRLD. (2018). Fees. Available: http://www.rld.state.nm.us/boards/

[74] NMP. (2018). About us. Available: https://nmpartnership.com/about-us/

[75] BFB. (2018). 3 Problems with Traditional Incubators and Accelerators. Available: https://medium.com/bridgeforbillions/3-problems-withtraditional-incubators-and-accelerators-a29354e30564

[76] TND. (2018). Public Service Professionals. Available: https:/www.teachernextdoor.us/Home-Buying-Programs

[77] Dentagraphics. (2018). State of New Mexico. Available: https://dentagraphics.com/new-mexico-infographic/

[78] Sokanu. (2018). How much does a Dentist make in New Mexico? Available: https://www.sokanu.com/careers/dentist/salary/new-mexico/

[79] R. Nott, "To separate lottery scholarships from tuition costs clears committee," The New Mexican, January 29, 2018. 